\title{
Interrogating patient-centredness in undergraduate medical education using an integrated behaviour model
}

\author{
E Archera*, EM Bitzerb and BB van Heerdenc \\ ${ }^{a}$ Centre for Health Professions Education, Stellenbosch University, Cape Town, South Africa \\ ${ }^{b}$ Centre for Higher and Adult Education, Stellenbosch University, Cape Town, South Africa \\ 'Faculty of Medicine and Health Sciences, Stellenbosch University, Cape Town, South Africa \\ *Corresponding author, email: elizea@sun.ac.za
}

Background: Patient-centredness, an approach that puts the patient at the centre of the consultation, thus focusing on patients instead of on his/her diseases, has been identified by most medical schools as a desired core competence of their graduates. Despite some curriculum initiatives, medical students often display a lack of patient-centredness upon graduation. This bears reason for concern and it was thus deemed important to explore possible factors that influence the teaching and learning of patient-centredness in an undergraduate medical curriculum. The article suggests a framework that can assist programme developers to conceptualise the teaching and learning of patient-centredness across an undergraduate curriculum.

Methods: A qualitative exploratory case study design was used for the study with final-year medical students. Themes of meaning were deduced from the data by employing components of an Integrated Behavior Model (IBM) of Fishbein.

Results: The findings of the study revealed that seven factors play a role: background characteristics of students, attitudinal factors, subjective norms (the hidden curriculum), student self-efficacy, acquired skills and knowledge, the environment or context within which patient-centredness is taught and learnt, as well as assessment of learning.

Conclusions: Patient-centredness is a complex construct and authors often write about only one of its components. This paper attempts to consider the total undergraduate medical curriculum students are exposed to when they learn about being patientcentred. The teaching and learning of such a multidimensional construct require a comprehensive approach in order to be effective and the IBM seems to be a useful and applicable theoretical model to apply.

Keywords: integrated behaviour model, patient-centredness, teaching and learning, undergraduate medical curriculum

\begin{abstract}
Introduction
Patient-centred medical care appears to be important in various respects: it can improve health outcomes, ${ }^{1}$ build caring relationships between patients and healthcare providers, ${ }^{1}$ increase patients' quality of life ${ }^{2}$ and at the same time increase doctor and patient satisfaction. ${ }^{3,4}$ It is thus not surprising that various authors, institutions and accrediting bodies ${ }^{5-7}$ recommend that the learning of patient-centredness needs to be an integral component in the design and offering of undergraduate medical curricula. The structure, content and delivery of undergraduate medical curricula have undergone important transformations over the last two decades, but it is still widely reported that positive attitudes and the idealism of first-year medical students often change to cynicism and paternalistic disease-centred attitudes as they progress through the curriculum. ${ }^{8-12}$
\end{abstract}

It is clear from the literature that patient-centredness is multifaceted and that a variety of constructs comprise this comprehensive concept. Some authors have suggested that because patientcentredness is not clearly defined it is not easy to measure, ${ }^{13}$ and it is probably for this same reason that one can argue that the teaching and learning thereof is also complex. The body of literature that informs the teaching and learning of patient-centredness in undergraduate medical programmes focuses to a large extent on the development of communication skills and empathy. ${ }^{14,15}$ Some authors do, however, acknowledge the importance of including other factors such as reflection and mindfulness ${ }^{16,17}$ as well as longitudinal clinical placements. ${ }^{10,18}$ Attempts to foster the development of patient-centredness in undergraduate medical curricula, however, often focus on only one or more factors, yet the interrelationship between the factors is poorly described.
The Integrated Behavior Model (IBM) (Figure 1) as proposed by Fishbein provides for the integration of various theories of behavioural change and is a useful framework to understand the complexity of integrating patient-centredness across a medical curriculum. ${ }^{19}$

According to this model a person's intention to perform or not perform a specific behaviour is the most important determinant of that action. Intention is a function of three determinants, namely attitudes, social influence and perceived behavioural control. The model further recognises that background factors can have a direct or indirect influence on behaviour. Finally the IBM takes into account that there are situations where one cannot act upon one's intentions, where the person needs the necessary skills and abilities to perform the behaviour and whether there are environmental constraints that may impede behaviour.

Patient-centredness in this study is viewed as a multi-dimensional construct, consisting of attitudinal and cognitive aspects as well as behavioural skills. While one does not have direct access to another person's thoughts and feelings, one can observe how attitudes or attributes result in behaviours and actions. What we propose in this article and what is new to the body of knowledge is a comprehensive theoretical framework that can be used to better understand the development and fostering of patientcentredness throughout an undergraduate medical curriculum.

\section{Aims and objectives of the study}

The purpose of the study was to explore the teaching and learning experiences of undergraduate medical students with 


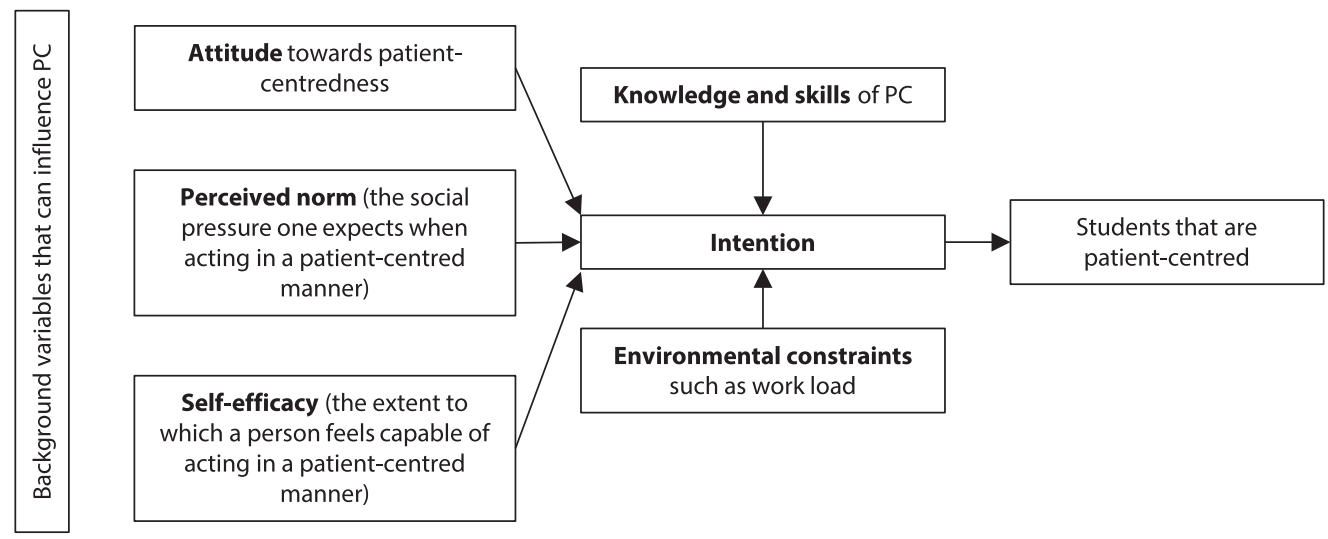

Figure 1: Model used to understand how students learn patient-centredness. Adapted Integrated Behavior Model of Fishbein (2003).

regard to patient-centredness in order to understand what factors enhance or inhibit the development thereof.

\section{Methods}

The study design comprised an exploratory case study making use of qualitative data. ${ }^{20} \mathrm{~A}$ case study research design can be utilised with more than one philosophical assumption in mind, and in this case it was from an interpretivist view. ${ }^{20}$ The population of the study was final-year medical students $(n=208)$ in 2014 with whom 10 focus-group interviews $(n=60)$ were conducted. This cohort was selected because they had almost completed their degree and could therefore evaluate and reflect on factors that enhanced or inhibited their learning of patient-centredness. Since research evidence shows that factors such as gender and cultural background might influence the attitudes of students towards patient-centredness, ${ }^{21,22}$ these two demographic aspects were considered when students were allocated to the various focus groups. All final-year students were invited to participate in the study via email, but participation was voluntary. One of the authors conducted the focus-group interviews and digital recordings were transcribed and anonymised by someone not involved in the research (see Table 1 for the prompts that were used as part of the interviews). All students signed informed consent before the start of each focus-group interview.Approval for the research was obtained from the Health Research Ethics Committee of the Faculty of Medicine and Health Sciences of Stellenbosch University (S13/09/167). The anonymity of the reported data for all participants was guaranteed and information was kept confidential at all times.

Table 1: Prompts that were used as part of the semi-structured focusgroup interviews

\section{What is meant by the term patient-centredness? How do you understand it?}

Think back to a consultation between a doctor and a patient that you observed either in a good or a bad way. Tell us about patient-centredness in that situation.

What in your opinion are the advantages and disadvantages of patient-centredness?

What are both the enablers and obstacles for students and doctors to be patient-centred?

Think back to when you first started to see patients here at medical school. What has changed in the way you interact with patients? Why do you think that is the case?

What incidents influenced your views and practices regarding patient-centredness?

\section{Data analysis}

The data analysis was done by the researcher and all transcripts were read several times in order to get a sense of the dataset. After that the analysis was done by making use of ATLAS.ti software (http://wws.atlasti.com). The elements of the IBM (Figure 1) were used as an analytical framework to organise the qualitative data into broad themes. In the analysis a constant comparative process was followed between the themes of the IBM and the data so that additional aspects that were evident in the data, but not present in the themes of the IBM, could be identified as new themes.

\section{Results}

By making use of the various elements of the IBM we gained an understanding of those factors that influence the learning of patient-centredness. The following data codes apply to the various illustrative quotes from focus-group interviews: $\mathrm{Gr}=$ group; $\mathrm{F}=$ female; $\mathrm{m}=$ male.

\section{Attitudes}

Participating students displayed an overwhelmingly positive attitude towards a patient-centred approach and they acknowledged that it is better for patients to be recognised and treated as a whole person with their own expectations. However, most students pointed out that, because they would generally see patients only for short and interrupted time periods in the clinical areas, they hardly ever got to know patients as 'complete persons.' The negative effect is thus that students sometimes have to remind themselves consciously that the patient is still a person and not only an item or a disease:

You can easily get lost in all the complexities of medicine, and then start de-personifying the patient. So it can become an intellectual puzzle for us and we forget in the end what it is about. (Gr7M2)

Conversely, students that did the longitudinal integrated clerkship at the Ukwanda Rural Clinical School (selected students who voluntarily do the whole final year in a district hospital), were the only ones who pointed to the benefits of getting to know patients beyond their diseases:

It starts with actually getting to know your patient, not just making sure you've ticked all the blocks on your history kind of thing, but actually getting to know the patient and then making management decisions with them. (Gr6F1) 
While patient-centredness encourages the attitude of an open doctor-patient relationship, there were comments that pointed to aspects of an old-fashioned paternalistic relationship:

... it's more efficient for you to take control of their health, because if you are going to negotiate, it's going to take up a lot more time, especially with the type of patients that we see here. They don't necessarily have the ability to take responsibility for their conditions. (Gr1F3)

In summary, with regard to attitudes towards patientcentredness, students seemed to view patient-centredness as the way medicine should be practised; however, contradictory to what they said they believe, various non-patient-centred attitudes emerged from the data.

\section{Subjective norms}

This theme relates to a person's belief that specific individuals or groups will approve or disapprove of their behaviour. Students tend to adapt to what the role models in the clinical areas view as important, thus emphasising the saying that behaviour is better learnt from example than from instruction:

Even if you are not actively being aware of what you are exposed to, you are taking it in somehow, and that becomes ingrained in you. You get used to the doctor that is doing it, so I'm going to do that. (Gr2F1)

Many examples of negative role modelling were highlighted during the interviews, yet students felt they could also learn from it if they could recognise it:

I think you must know how you must be; you must see how to do it and how not to do it. So it is important to have bad role models to see how you mustn't do it. (Gr5M2)

Overall, participating students mentioned many examples of negative role models rather than positive ones, and although they appreciated the good examples they also learnt from bad ones.

\section{Self-efficacy}

The IBM states that self-efficacy may be based on past experience with a required behaviour, so having had opportunities to practise patient-centredness previously may have a strong effect on a student's belief in his/her ability to perform such behaviour recurrently. Students who were interviewed commented that they could not implement the approach they had been taught in medical school:

If you want to see the patient holistically you slow the system down and the other patients wait even longer. (Gr4F3)

It was only those students doing the longitudinal rotations that verbalised some confidence concerning being patient-centred. A comment from one student in this rotation was:

I'm so glad I learnt it so that even if I go back into a tertiary setting, I can still use it there, or it should still at least be my approach to be patient-centred and not just focus on biological functioning. (Gr6M1)
Generally students who participated in the study did not perceive themselves capable of being patient-centred in the complex and time-pressured clinical environments where they were learning and working.

\section{Background factors}

Background factors that were mentioned in the group interviews were gender, age and personality. Students were of the opinion that personality plays a major role in the way doctors approach patients:

You cannot teach somebody to be something that he is not. You can't teach somebody an aptitude that they don't have. For example you cannot take anybody from the street and make them a $100 \mathrm{~m}$ Olympic athlete. (Gr4M1)

The IBM recognises that background factors of individuals are important and that they may have an influence on required behaviour.

\section{Skills and knowledge}

The IBM recognises that even if students have the intention to be patient-centred, they need the appropriate skills and knowledge together with an environment that is conducive to patientcentred behaviour. ${ }^{23}$ From the students' observations it would seem as if they had fairly good theoretical knowledge about what patient-centredness was, but they felt they were not taught the necessary skills to apply this attribute in clinical areas:

I never actually heard a doctor say to a student, 'Do you think that you interacted appropriately with that patient?' I have in fact never heard any comment given on the way a student interacted with a patient. (Gr4F1)

We are left on our own to learn the whole patient-centred approach, because there is so much academic things to push into a very limited amount of time. (Gr1M1)

Despite the fact that the students were taught various aspects of patient-centredness during their training they could not recall when and where they were taught specific components thereof.

\section{Environment}

Factors related to their clinical learning mentioned by students included aspects such as limited resources and system failures.

Furthermore it was clear from the data that the need or the pressure to be patient-centred was also influenced by the environment or discipline in which the students were working:

I've been told by the registrar, on one of my rotations when I made time to sit down with a patient that was emotional, that if I want to spend time on emotions, [to] go and do Family Medicine: 'We don't have time to do this. We have a lot of work to do.' (Gr8F5)

\section{Assessment as a driving force}

One aspect that the IBM structure did not specifically account for was the students' comments concerning the assessment of patient-centredness. It would seem that assessment is seen by the students as a final motivating factor to be patient-centred or not: 
I find myself under so much pressure to be on academic level on ward rounds that my focus is not on the patient's socio-economic status. I want to know what your problem is, is it ulcerative colitis, good, and then I am so focused ... if the consultant comes I can give him all the facts. I only have enough time to sleep and study about ulcerative colitis, so I can tell him everything about ulcerative colitis. I don't care about the patient, I've got no time. That is the reality.... Because I hate embarrassment. I hate feeling stupid. (Gr5F4)

It was also evident that whether students behave in a patientcentred manner or not is strongly influenced by reigning assessment practices and students stated that they would value patient-centredness more if it was assessed more rigorously:

I think you can't make someone to be a people's person, but I think you can enforce the whole patient-centredness as a skill. Make it compulsory in all your evaluations, no matter what block, by your psychosocial as part of the assessment. If you do not have this aspect, they must mark you down. Then it will force people to start thinking about it and it will become second nature for everybody later on. (Gr3F2)

\section{Discussion}

The data collected in this study enabled us to identify a number of factors that need to be considered when patient-centredness is learned and taught, highlighting that a patient-centred curriculum needs to be comprehensive and longitudinal in nature. Furthermore, the IBM proved to be a useful framework for the conceptualisation of how the learning of patientcentredness can be implemented and integrated in an undergraduate medical curriculum. A new factor that was added to the model was assessment, since assessment was a seen as a final factor that has a significant influence on how students behave.

First, the attitudes of students need to be seen as a crucial aspect of future behaviour in practice. Acknowledging that a curriculum cannot necessarily change students' attitudes, students can be exposed to learning opportunities that enhance positive attitudes. This study showed that students who were placed in short clinical rotations lack sufficient opportunities to get to know their patients and see them holistically, highlighting the fact that the nature of a clinical placement is important. This concurs with studies which suggest that medical students who are exposed to short clinical rotations often become diseasecentred, hence longitudinal integrated clerkships are advised. ${ }^{24}$

Second, this study confirmed the importance of self-efficacy of medical students. When proper role modelling and feedback on learning are combined with sufficient opportunities for practical experiences, students may be assisted in developing their sense of self-efficacy and thus the patient-centred behaviour that they intend to perform..$^{25}$ Crucial aspects that therefore need to part of a patient-centred curriculum are several opportunities where students can observe and practice patient-centredness both in simulation and in the clinical areas. This should be followed by feedback and reflection opportunities.

Third, attention to subjective norms or the clinical environment is vital. Clinicians need to be aware of the important impact of rolemodelling on the development of undergraduate medical students' behaviour. While doctors in the clinical areas need to make their actions overt in order to create opportunities for students to reflect critically on their behaviour as part of clinical learning, students also need to be guided to develop a sense of self-reflection so that they can distinguish between the exemplary and non-exemplary role models they are exposed to. ${ }^{26}$

Fourth, in terms of the background factors that Fishbein's Integrated Model describes, our study highlighted the personality of an individual as a particularly strong factor that could have a direct influence on patient-centredness. This aspect should thus be considered more prominently in student selection and admission procedures. This finding resonates with the argument that some attributes cannot be taught and that selection criteria should consider these. ${ }^{27-29}$

While the factors discussed up to now can assist students to develop a positive inclination towards patient-centredness, two further factors that need to be accounted for as part of a comprehensive undergraduate medical curriculum would be the environment and skills and knowledge.

With regard to the environment, students in our study experienced their exposure to environments where they were overworked, and often cynical doctors were present, as hindering their development towards positive attitudes and skills regarding patient-centredness. The other hindering factor pointed to systems issues such as staff shortages and ill-equipped environments-aspects that might not be under the direct control of the training institution. This calls for students' selfefficacy so that they can be patient-centred despite an environment that is not conducive to patient-centredness. Alternatively, it might call for more careful student placementsin areas that are more conducive to patient-centredness.

While skills and knowledge are important aspects in the development of patient-centredness, any of the individual elements comprising such knowledge and skills, for example communication skills, empathy, compassion, etc., should not be seen as being enough. All of these elements should form part of a carefully planned comprehensive patient-centred curriculum. Since communication skills and theoretical knowledge related to a patient-centred approach can be readily taught, this again highlights the necessity of a well-planned communication skills course as part of a medical programme..$^{30}$

The final key in the development of patient-centredness seems to be a holistic and integrated assessment of patient-centredness. Assessment could thus be used as an important driving force for medical students to develop patient-centredness. It has been advised that the impact of assessment of student learning can be considered as one of the fastest ways to change and enhance student learning and behaviour. ${ }^{31}$

\section{Limitations}

This study has several limitations. Since a case study approach was used for this study, its findings and implications are contextbound; therefore, if the study were to be repeated elsewhere the results might differ. However, a high level of trustworthiness and ecological validity was ensured in the study by making use of senior student observations, as well as original and programmerelated data sets. One may thus expect to find similar results in contexts that are similar.

\section{Conclusion}

This paper is the first of its kind to have attempted to discuss the total curriculum that needs to be considered in the development of patient-centredness. It is recommended that the teaching and 
learning of a construct as multidimensional as patientcentredness needs a comprehensive approach and the Integrated Model of Fishbein seems to be a useful theoretical model to apply. This study further points to a need for a jointly planned and well-coordinated approach to the formal, informal and hidden curriculum spaces within a medical curriculum with well-trained clinician teachers/faculty members who understand the importance and application of patient-centredness in modern medical practice.

Acknowledgements - The authors wish to thank the students who took part in the study as well as acknowledging the funds that were made available by SURMEPI to do the research.

Declaration of interest - The authors have declared that there are no conflicts of interest.

\section{References}

1. Mead N, Bower P, Hann M. The impact of general practitioners' patient-centredness on patients' post-consultation satisfaction and enablement. Soc Sci Med. 2002 Jul 31;55(2): 283-99. https://doi. org/10.1016/S0277-9536(01)00171-X

2. Lewin SA, Skea ZC, Entwistle V, et al. Interventions for providers to promote a patient-centred approach in clinical consultations. Cochrane Database Syst Rev. 2001 Jan 1;4(10):1-64.

3. Lorig K. Partnerships between expert patients and physicians. The Lancet 2002 Mar 9;359(9309):814-5. https://doi.org/10.1016/S01406736(02)07959-X

4. Oates J, Weston WW, Jordan J. The impact of patient-centered care on outcomes. Fam Pract. 2000;49:796-804.

5. Frank JR, Snell LS, Sherbino J. CanMEDS. Physician Competency Framework; 2015 [cited 2017 September 25]. Available from: http:// canmeds.royalcollege.ca/en/framework

6. Little P, Everitt H, Williamson I, Warner G, Moore M, Gould C, Ferrier $\mathrm{K}$, Payne S. Observational study of effect of patient centredness and positive approach on outcomes of general practice consultations. BMJ. 2001 Oct 20;323(7318):908-11. https://doi.org/10.1136/ bmj.323.7318.908

7. Lévesque M, Hovey R, Bedos C. Advancing patient-centered care through transformative educational leadership: a critical review of health care professional preparation for patient-centered care. J Healthcare Leadership. 2013;5:35-46. https://doi.org/10.2147/JHL

8. Bombeke K, Symons L, Debaene L, et al. Help, I'm losing patientcentredness! Experiences of medical students and their teachers. Med Educ. 2010 Jul 1;44(7):662-73. https://doi.org/10.1111/med.2010.44. issue-7

9. Haidet P, Dains JE, Paterniti DA, et al. Medical student attitudes toward the doctor-patient relationship. Med Educ. 2002 Jun 1;36(6):568-74. https://doi.org/10.1046/j.1365-2923.2002.01233.x

10. Krupat E, Pelletier S, Alexander EK, et al. Can changes in the principal clinical year prevent the erosion of students' patient-centered beliefs? Acad Med. 2009 May 1;84(5):582-6. https://doi.org/10.1097/ ACM.0b013e31819fa92d

11. Archer E, Bezuidenhout J, Kidd M, et al. Making use of an existing questionnaire to measure patient-centred attitudes in undergraduate medical students: a case study. Afr J Health Prof Educ. 2014;6(2):150154.

12. Ribeiro MM, Krupat $E$, Amaral CF. Brazilian medical students' attitudes towards patient-centered care. Med Teach. 2007 Jan 1;29(6):e204-8. https://doi.org/10.1080/01421590701543133

13. Mead N, Bower P. Patient-centredness: a conceptual framework and review of the empirical literature. Soc Sci Med. 2000 Oct 1;51(7):1087110. https://doi.org/10.1016/S0277-9536(00)00098-8

14. Stepien KA, Baernstein A. Educating for empathy. J Gen Intern Med. 2006 May 1;21(5):524-30. https://doi.org/10.1111/j.15251497.2006.00443.x
15. Silverman J. Teaching clinical communication: A mainstream activity or just a minority sport? Patient Educ Couns. 2009 Sep 30;76(3): 3617. https://doi.org/10.1016/j.pec.2009.06.011

16. Shapiro J, Rucker L, Robitshek D. Teaching the art of doctoring: an innovative medical student elective. MedTeach. 2006 Jan 1;28(1):30-5 https://doi.org/10.1080/01421590600568348

17. McConville J, McAleer R, Hahne A. Mindfulness training for health profession students-the effect of mindfulness training on psychological well-being, learning and clinical performance of health professional students: a systematic review of randomized and non-randomized controlled trials. EXPLORE: The Journal of Science and Healing 2017 Feb 28;13(1): 26-45. https://doi.org/10.1016/j explore.2016.10.002

18. Ogur B, Hirsh D, Krupat E, Bor D. The Harvard medical schoolcambridge integrated clerkship: an innovative model of clinical education. Acad Med. 2007 Apr 1;82(4):397-404. https://doi. org/10.1097/ACM.0b013e31803338f0

19. Fishbein $M$, Yzer MC. Using theory to design effective health behavior interventions. Commun Theory. 2003 May 1;13(2):164-83. https:// doi.org/10.1111/comt.2003.13.issue-2

20. Merriam SB, Tisdell EJ. Qualitative research: a guide to design and implementation. San Francisco, CA: John Wiley \& Sons; 2015. https:// doi.org/10.4018/AKATM

21. Quince TA, Kinnersley $P$, Hales J, et al. Empathy among undergraduate medical students: a multi-centre cross-sectional comparison of students beginning and approaching the end of their course. BMC Med Edu. 2016 Mar 15;16(1):92. https://doi.org/10.1186/s12909-0160603-7

22. Van Winkle LJ, Fjortoft N, Hojat M. Impact of a workshop about aging on the empathy scores of pharmacy and medical students. Am Pharm Educ. 2012 Feb 10;76(1):9. https://doi.org/10.5688/ajpe7619

23. Yzer M. The integrative model of behavioral prediction as a tool for designing health messages. Health Communication Message Design: Theory and Practice 2012:21-40.

24. Maley $M$, Worley $P$, Dent J. Using rural and remote settings in the undergraduate medical curriculum: AMEE Guide No. 47. Med Teach. 2009 Jan 1;31(11):969-83. https://doi. org/10.3109/01421590903111234

25. Young HN, Schumacher JB, Moreno MA, et al. Medical student self-efficacy with family-centered care during bedside rounds. Academic Medicine: Journal of the Association of American Medical Colleges. 2012 Jun;87(6): 767. https://doi.org/10.1097/ ACM.0b013e318253dcdb

26. Benbassat J. Role modeling in medical education: The importance of a reflective imitation. Acad Med. 2014 Apr;89(4): 550. https://doi org/10.1097/ACM.0000000000000189

27. Gordon J. Fostering students' personal and professional development in medicine: a new framework for PPD. Medical Education. $2003 \mathrm{Apr}$ 1;37(4): 341-9. https://doi.org/10.1046/j.1365-2923.2003.01470.x

28. Prideaux D, Roberts $C$, Eva $K$, et al. Assessment for selection for the health care professions and specialty training: consensus statement and recommendations from the Ottawa 2010 conference. Med Teach. 2011 Mar 1;33(3): 215-23. https://doi.org/10.3109/014215 9X.2011.551560

29. Magalhães E, Costa P, Costa MJ. Empathy of medical students and personality: evidence from the Five-Factor Model. Med Teach. 2012 Oct 1;34(10):807-12. https://doi.org/10.3109/0142159X.2012.702248

30. Silverman J, Draper J. Teaching and learning communication skills in medicine. London: Radcliffe Publishing; 2005.

31. Cilliers FJ, Schuwirth LW, Adendorff HJ, et al. The mechanism of impact of summative assessment on medical students' learning. Adv Health Sci Educ. 2010 Dec 1;15(5): 695-715. https://doi.org/10.1007/ s10459-010-9232-9 